\title{
UMA RELAÇÃO ENTRE VAQUEIROS E SEUS ANIMAIS NO SERTÃO PERNAMBUCANO
}

\author{
A RELATIONSHIP BETWEEN \\ CAWBOYS AND THEIR ANIMALS IN \\ PERNAMBUCANBUSHLAND
}

\author{
Maximiliano Carneiro-da-Cunha \\ maxcarneiro6@gmail.com \\ Universidade Federal Rural de Pernambuco - UFRPE/UAST \\ Andiara Valentina de Freitas e Lopes \\ andiaralopes@yahoo.com \\ Universidade Federal de Pernambuco - UFPE
}

\section{RESUMO}

A relação entre humanos e animais é de grande importância no nosso cotidiano, mesmo que isto não seja sempre claro para a maioria de nós. Essa relação tem sido objeto de crescente interesse por pesquisadores de diversas áreas do conhecimento nas últimas décadas, através dos Estudos da Relação Humano-Animal. Este artigo tem como foco a vida dos vaqueiros pernambucanos e sua relação com os animais com os quais convivem constantemente, seja no trabalho diário ou nas competições de habilidades, nas Pega de Boi e nas Vaquejadas. Essa relação mostra a relevância do desenvolvimento da região do Pajeú, no sertão pernambucano, que faz parte de um dos ciclos econômicos da história do Brasil, o da pecuária. Da mesma forma, ela revela como o desenvolvimento de uma cultura local, hoje considerada patrimônio cultural e imaterial, contribuiu para o crescimento da pecuária no país.

Palavras-chave: Vaqueiros. Estudos sobre animais. Estudosculturais. Sertão.

\begin{abstract}
The relationship between humans and animals is of great importance in our daily life even if it is not always clear to most of us. This relationship has been the subject of growing interest by researchers from various fields of knowledge in recent decades, through the study of the Human-Animal Studies. This article focuses on the lives of Cowboys from Pernambuco and its relationship to the animals with which they live constantly in daily work or in skill competitions, such as the Pega de Boi and Vaquejadas. This relationship displays the importance of the development of the Pajeú region, in the hinterlands of Pernambuco, which was part of one of the economic cycles in the history of Brazil, the livestock farming as well as the development of a local culture, now considered cultural and intangible heritage, contributed to the growth of livestock in the country.
\end{abstract}

Keywords: Cowboys. Animal studies. Cultural studies. Bushland. 


\section{INTRODUÇÃO}

Os animais estão presentes em nossas vidas mais do que podemos imaginar. Sejam como animais de estimação, como transporte, como trabalho, como alimento ou como vestimenta, os animais fazem parte de nosso dia a dia, mesmo que isso não seja percebido pela grande maioria dos humanos. Dentro da história da humanidade, a presença de animais está intimamente ligada ao nosso desenvolvimento como espécie, estando presentes nas religiões, nas artes e na nossa vida diária.

Os estudos sobre humanos e animais, mais especificamente dentro do campo das ciências sociais e humanidades, têm se desenvolvido bastante nos últimos anos. Essas investigações vêm preencher uma lacuna que, cada vez mais, tem sido alvo de interesse por parte de pesquisadores em diversas áreas do conhecimento, ou seja, as relações entre humanos e animais e de como elas afetam nossa vida. Tudo isso levanta questões tais como os direitos dos animais, sua importância como elementos afetivos em nossas casas, sua importância dentro do nosso diaadia, entre outros temas.

Na mesma direção desses estudos, a presente pesquisa tem como foco a relação entre os vaqueiros e os animais que estão presentes em suas vidas, mais especificamente cavalos e gado, no sertão do estado de Pernambuco, cuja cultura do vaqueiro ainda se faz viva e resiliente. $O$ grau de relevância dessa relação pode ser entendido através da maneira como a pecuária foi trazida e desenvolvida no Brasil, passando a ser um dos setores econômicos de significativo valor, bem como o elemento cultural na figura do vaqueiro nordestino tão evocado na literatura e arte brasileira.

As abordagens teóricas neste artigo foram embasadas na associação entre a antropologia - e os estudos culturais - com os estudos sobre animais (Animal Studies), já que a relação entre humanos e animais aqui se baseia na tradição cultural do vaqueiro do sertão pernambucano. Sendo parte de uma ampla pesquisa sobre o vaqueiro pernambucano e seus costumes culturais, este estudo vem em parte de um levantamento bibliográfico sobre estudos entre humanos e animais, além de uma etnografia sobre os vaqueiros no sertão de Pernambuco.

Sendo assim, o intuito é de contribuir para os estudos sobre a relação entre humanos e animais, que vem crescendo em interesse não só por parte de cientistas do campo das ciências naturais, mas também para os pesquisadores das ciências sociais e humanidades em geral.

\section{OS ESTUDOS SOBRE A RELAÇÃO ENTRE HUMANOS E ANIMAIS}

Nos últimos trinta anos, um novo campo de conhecimento passou a ganhar mais espaço dentro dos estudos acadêmicos enfocando a relação entre e humanos e animais. Vários autores atribuem o início dessa nova área de conhecimento e um crescente interesse por parte da academia sobre os animais e seu papel dentro das sociedades humanas às publicações de dois importantes trabalhos envolvendo animais e humanos: Animal Liberationde Peter Singer, seguida de The Case for Animal Rights de Tom Regan. A razão disso se deu em grande parte devido à negligência acadêmica dada aos animais e as relações com os seres humanos, especialmente pela difusão das formas de representações simbólicas dos animais, assim como pelas histórias narradas nas diversas culturas humanas. (SHAPIRO; DEMELLO, 2010). 
Desde 1987, esse campo passou a ser conhecido por várias nomenclaturas, comoAnthrozoölogy, Estudos de Animal, Estudos Críticos de Animal, Estudos de Animais e Sociedade, Humanimalia e o nome pelo qual tornou-se mais conhecido: Estudos humano-animal ou, no original, Human-Animal Studies (HAS). Essa dificuldade em estabelecer um nome que se acomodasse às diversas disciplinas que o campo engloba, reflete questões mais profundas sobre um estatuto dos animais que trará, possivelmente, uma aceitação e consequente progresso desse campo que lida com as nossas relações com os animais que nos cercam cotidianamente. (SHAPIRO, 2008).

Para manter uma denominação comum durante o desenvolvimento desse artigo, e na falta de uma nomenclatura definida da área no Brasil, passarei a chamar o campo de "Estudo das Relações Humano-Animal", sem sigla como no original (HAS - Human-animal Studies). Para uma melhor compreensão, podemos dizer que esse é um campo interdisciplinar/multidisciplinar que visa explorar as formas através das quais os animais ocupam as sociedades humanas, levando em conta as interações e relações entre humanos e animais (ou animais não-humanos). $\mathrm{O}$ foco central desse campo de estudo está nas formas com que a vida dos animais se sobrepõe, temporalmente e espacialmente, com os humanos. (DEMELLO, 2012). Contudo, não se pode equivocadamente entender essa área do conhecimento como o estudo de animais, como nas ciências naturais. $\mathrm{Na}$ verdade, o objetivo do Estudo das Relações Humano-Animal é analisar as interações entre seres humanos e animais quando essas interações ocorrerem dentro de nossas vidas.

Os diversos acadêmicos que estão envolvidos com o Estudo das Relações Humano-Animal têm procurado compreender a distinção entre o animal "tal como ele é" e o animal como "socialmente construído", na mesma concepção em que idealizamos o "outro", concepção essa tão comum à Antropologia. Sociologicamente falando, temos por hábito nos cercar de entendimentos antropocentricamente construídos, pois mesmo que os animais pertençam à natureza em sua essência, eles são incorporados ao nosso mundo social com atribuições categóricas que nós lhes oferecemos. O problema que se revela aqui é que esses conceitos estão fortemente impregnados de conceitos ideológicos que servem apenas aos nossos próprios interesses. (SHAPIRO; DEMELLO, 2010).

Nós, humanos, não podemos negar que estamos constantemente rodeados de animais em nossas vidas. Nós nos alimentamos de animais - e dos produtos que usualmente são adquiridos através deles (leite, carne, mel) - nos vestimos com roupas e sapatos que, em diversos casos, são constituídos por couro, pelo ou lã de animais. Nós usamos medicamentos que são criados através do uso de cobaias em laboratórios, assim como usamos no nosso diaadia, produtos cosméticos que são repetidamente testados em animais. (INGOLD, 1988; WALDAU, 2013).

Os animais são, desse modo, encontrados em praticamente todas as tradições nas sociedades humanas. Nós colocamos em nossas casas diferentes tipos de animais, como animais de estimação e, não raro, são tratados como membros da família. Além do mais, nós os representamos nas diversas formas de arte (literatura, pintura, contos, música), nos esportes como mascotes e os usamos em circos, em museus e jardins zoológicos e, nesse último caso, nem sempre bem tratados e respeitados. (MARVIN; MCHUGH, 2014). Contudo, enquanto alguns animais chegam a nossas casas como animais de estimação, outros são na maioria dos casos tratados e entendidos como invasores, e por essa razão, passíveis de maus tratos e até mesmo extermínio, estabelecendo assim uma dicotomia domesticado $\mathrm{x}$ selvagem ou estimação $\mathrm{x}$ fera (LEWGOY;SORDI;PINTO, 2015). 
Na introdução de TheorizingAnimals, Nik Taylor (2011, p. 1) afirma:

\begin{abstract}
"Animals have become the increasing focus of academic interest, an interest which spans multiple disciplines and begins to question hitherto taken for granted assumptions about the place of animals and their relationship vis a vis humans. Recent evidence regarding environmental problems and changes has led to an increased awareness of the inter-connectedness of all life which in turn has led (is leading?) to a rejection of the human-centered - anthropocentric - assumptions which are considered to be indicative of current ways of seeing animals. If humans are no longer 'the centre of the universe' and if our relations with animals are much more complex than previously thought, then we need to study them in new - and diverse - ways; in ways which continue to challenge us to re-think 'our' relationships with 'them'. This then serves to legitimize much of the current interest in animals from disciplines previously largely concerned only with humans (i.e. the social sciences and the humanities)".
\end{abstract}

Não há como deixar de reconhecer que a antropologia sempre abordou os animais dentro de seus estudos sobre a humanidade e suas diversas formas de cultura, mesmo que de forma simbólica ou representativa. (DEMELLO; JOSEPH, 2010). Desde a perspectiva biológica, passando pela arqueologia e questões sociais e culturais, a antropologia continuamente tem enfocado, de alguma maneira, a presença de animais dentro de suas investigações. Isso sem mencionar o fato de inúmeras divisões dentro da área, tais como Antropologia Econômica, Antropologia Política, Antropologia da Doença, dentre outras, graças à interdisciplinaridade inerente à disciplina, o que faz com que antropólogos transitem em diferentes campos do conhecimento, seja nas ciências naturais, sociais ou humanidades. Entretanto, o escopo, as abordagens teóricas e metodológicas diferem significativamente das outras áreas, tornando o enfoque sobre as relações entre humanos e animais particularmente difícil.(MULLIN, 1999 e 2002; TAYLOR, 2011).

Embora o campo tenha começado nas ciências humanas, mas especificamente na filosofia com o livro Animal Liberationde Peter Singer, como dito anteriormente, a área ganhou grande desenvolvimento nas ciências sociais e nas humanidades. Estudos em outras disciplinas das ciências sociais e humanas (Antropologia, Geografia, Ciências Políticas e Direito) foram publicados em seguida, criando um grupo de estudiosos cada vez maior nos estudos sobre a relação humano-animal. Pode-se dizer que os animais sempre serviram como objetos de estudo nas ciências naturais e sociais, mas raramente foram considerados como sujeitos ao invés de objetos de estudo. Talvez pelo fato de que os humanos sempre tenham usado os animais de diversas formas em nossa sociedade, tais como o consumo de carne ou nos diversos experimentos médicos, mas esquecendo que os animais possuem também subjetividade. (DEMELLO, 2012).

A antropologia, mais do que qualquer outra disciplina nas ciências sociais e humanas, não poderia negligenciar os estudos envolvendo humanos e animais, pois sempre teve como base a compreensão e entendimento das culturas e as relações humanas envolvendo animais e sua relevância dentro das sociedades. Por essa razão, os animais sempre estiveram presentes nos primeiros trabalhos desenvolvidos na disciplina, já que os animais sempre foram altamente significativos em muitas das sociedades estudadas pelos antropólogos e faziam parte do cotidiano da maioria das sociedades no mundo. (MARVIN; MCHUGH, 2014). Desde obras clássicas como Os Nuer de Evans Pritchard ou A Interpretação das Culturas de Clifford Geertz, os animais fazem parte dos relatos etnográficos. Porém, não deixa de ser surpreendente observar que só recentemente os estudos antropológicos se voltaram para as relações entre humanos e animais, 
dando maior importância à produção de significados relacionados à presença deles na nossa cultura.

E mesmo que os antropólogos ainda não estabeleçam nenhuma forma de cultura para os animais não-humanos, pode-se dizer que a disciplina possui um grande apelo para a área de Estudos da Relação Humano-animal, graças em parte à sua particularidade de estabelecer laços entre pesquisador (a) e seu objeto, oferecendo uma maior subjetividade ao invés do distanciamento encontrado em outras disciplinas. Especialmente pelo fato de ter uma metodologia de participação observante, o que propicia uma representação mais próxima da realidade no que diz respeito ao papel dos animais nas sociedades humanas. (DEMELLO, 2012).

Em suma, em todas as nossas formas de viver em sociedade, nós sempre nos encontramos até mesmo dependentes dos animais de um jeito ou de outro. Não há como escapar de termos que levar em consideração estudos que retratem os animais de acordo com o grau de importância que eles têm nas nossas sociedades. Certamente, não é intenção deste artigo estabelecer uma abordagem definida ou até mesmo esclarecedora, uma vez que as diferentes formas de culturas e de relacionamentos entre humanos e animais varia enormemente de acordo com cada contexto, além do fato de que os interesses da área são diversos, incluindo direitos dos animais, animais de estimação, maus tratos, questões éticas, entre outros temas. Consequentemente, isso não seria diferente entre os vaqueiros pernambucanos e os animais em sua rotina e meio ambiente, especialmente se considerarmos que há mais de um tipo de relacionamento entre humanos e animais neste caso.

\section{VAQUEIROS E A PECUÁRIA NO SERTÃo DE PERNAMBUCO}

Podemos dizer que a colonização do interior do Nordeste engloba três aspectos indissociáveis: a concessão de terras (sesmarias), a catequização dos povos indígenas nativos e a ocupação da região pela pecuária, através das fazendas de gado. Dentro deste processo, a estrutura social do interior nordestino era composta pelo donatário, os fazendeiros, e os vaqueiros que se constituíam na força de trabalho no sistema produtivo para o trato com o gado. (NUNES, 2011)

No fim do século XVIII, a economia brasileira se apresentava em torno de dois polos principais, a saber: as economias do açúcar e a do ouro. No núcleo econômico açucareiro encontrava-se a pecuária nordestina, responsável em grande parte pela ocupação do interior do Brasil na época colonial. E, ao contrário da economia açucareira, a economia pecuária, através da criação de gado, representava um mercado de extensões bem mais restritas, limitada basicamente à própria subsistência da população nordestina. Para Caio Prado Júnior (1985), a pecuária no Nordeste não possuía grande produtividade por várias razões.Entre elas, terras com pouca fertilidade para o pasto, escassez de água, a pouca alimentação disponível, ataques de índios e fuga do gado dos currais.

É nesse contexto que o vaqueiro se apresenta e passa a ter uma relação com os animais de forma intensa, mais especificamente, com o gado e seu cavalo. A relação com o gado é difícil, pois esses animais são geralmente criados soltos, e para alcançá-los, os vaqueiros são obrigados a entrar na vegetação do sertão pernambucano, composta por plantas carregadas de espinhos e galhos secos, que não apenas dificultam o manuseio do gado, mas também oferecem perigo para aqueles que se embrenham mata adentro. São inúmeros os casos de acidentes envolvendo vaqueiros caindo de seus cavalos ou até mesmo serem 
atingidos por esse tipo de vegetação da caatinga que envolve braços e pernas quebrados, perda de visão, espinhos dentro do corpo, entre outros.

A pecuária foi, sem dúvida, o principal fator da ocupação do território nordestino, cuja função era a de abastecer as maiores populações que se localizavam nas áreas litorâneas, através do fornecimento de carne e couro. Nesse sentido, Pernambuco e Bahia se encontravam como os maiores produtores, com o sertão subdividido entre o Sertão da Capitania da Bahia e o Sertão de Pernambuco. (ANDRADE, 1986).

No processo de colonização portuguesa, expedições compostas por vaqueiros e missionários foram enviadas ao sertão, com as criações de gado se expandindo pelo interior nordestino. Nesse sentido, o vaqueiro era um elemento de vital importância na pecuária do nordeste, já que eles eram responsáveis em boa parte pela manutenção da fazenda, tendo como função fiscalizar as pastagens e as aguadas, providenciar sua instalação e defesa, necessitando de um grande número de auxiliares até que o gado se adaptasse às novas pastagens. O pagamento vinha após alguns anos de trabalho, quando o vaqueiro passava a receber a "quarta" em reses nascidas. (SILVA, 2003). De acordo com os estudos de Manoel Correia de Andrade (1986) sobre o tema, a forma de remuneração, também denominada de "quartiação", representava para os vaqueiros a maneira pela qual eles podiam se tornar também proprietários de animais e, futuramente, constituir seu próprio rebanho, mesmo que pequeno.

Através do sistema de doação das sesmarias, algumas famílias foram agraciadas com lotes de terra no interior nordestino com grandes propriedades nos Sertões presenteadas pela coroa portuguesa. A pecuária, dessa forma, tornou-se a base econômica do sertão, com fazendas pequenas possuindo uma média de duzentas ou trezentas cabeças de gado e por volta de trinta cavalos, enquanto que as grandes fazendas chegavam a possuir cerca de oitocentas mil cabeças de gado. $\mathrm{O}$ vaqueiro, elemento humano necessário para levar adiante a força de trabalho nas fazendas, foi representado assim pelo mameluco, que era homem livre e tornou-se o integrante "mais característico da região" e do Brasil. (SILVA, 2003).

Ambos os sistemas econômicos do nordeste brasileiro - o ciclo do açúcar e a pecuária - começam a dar sinais de fadiga, e logo se inicia um lento processo de declínio na segunda metade do século XVII, o que, segundo Celso Furtado (1967), iria se caracterizar como as bases para o que se tornaria a economia brasileira nos séculos seguintes. Após esse período, que se prolonga até o início do século XX, a economia nordestina sofreu um lento processo de atrofiamento, no sentido de que a renda real per capita de sua população declinou expressivamente. Dessa forma, a região nordeste do Brasil foi se transformando gradativamente em uma economia na qual a maior parte da população produzia apenas o necessário para a sua subsistência. (FURTADO, 2007).

\section{OS VAQUEIROS E SEUS ANIMAIS}

Uma etnografia tendo como foco os vaqueiros e sua cultura não é uma etnografia no sentido tradicional do termo, uma vez que os vaqueiros não se constituem em uma comunidade fixa e definida. Ao contrário, eles se encontram em cidades e áreas rurais diversas e possuem características e culturas diferentes, já que variam em relação às relações com os animais, ao tipo de trabalho, moradia, idade, entre outros aspectos. Vaqueiros, como veremos mais adiante, se dividem em diferentes contextos espaciais e temporais, estabelecendo suas relações com os animais de forma distinta. Se isso torna a pesquisa de campo 
uma tarefa complicada, imagine quando adicionamos a esse fato outros sujeitos, ou o que Kirksey e Helmreich (2010, p. 545) chamam de etnografia entre espécies, um novo gênero de escrita e modo de pesquisa que chegou no universo antropológico: multispeciesethnography. Por essa razão, é preciso entender um pouco de cada um dos atores dentro dessa relação, que se manifesta principalmente através das relações entre humanos, gado e cavalos neste cenário. (RAPCHAN; NEVES, 2014).

A forma que os vaqueiros pernambucanos se relacionam com os animais varia, dependendo do contexto em que se encontram. Já nos primeiros contatos com esses vaqueiros percebe-se que há dois tipos básicos de vaqueiros, de acordo com eles. De um lado, temos o vaqueiro que vive do trabalho em fazendas e que possui uma relação diária com o(s) seu(s) cavalo(s) e o gado. Eles são chamados pelos vaqueiros em geral de "vaqueiro do campo" e vivem de um salário mensal para manusear e tratar o gado, seja esse gado propriedade sua ou de algum fazendeiro da região. Por outro lado, temos o "vaqueiro de pista", que é geralmente um vaqueiro urbano e que só entra em contato com os animais, cavalo e gado, no momento em que participa de torneios como a "Pega de boi" ou a "Vaquejada". Esse tipo de vaqueiro não tem o trabalho com o gado no seu dia a dia, lidando com os animais apenas nesses eventos competitivos.

Em se tratando do vaqueiro do campo, este tem como atividade principal a "campeada"', que consiste em tocar ou tanger o gado ao campo (mata), já que o gado é criado solto nas pastagens das caatingas. Isso ocorre porque frequentemente o gado sai dos limites de uma fazenda em busca de outras pastagens. A campeada é feita com o auxílio do cavalo, elemento sinequa non para a atividade já que a vegetação da caatinga é, com já foi dito, perigosa e de difícil acesso. Usualmente os vaqueiros aprendem a campear com a família, prática que costuma ser passada adiante e acaba seperpetuando a cada nova geração. Além da campeada - que consiste em recolher o gado após o período de chuvas ou quando o gado está apto para a venda, depois da engorda - os vaqueiros também são responsáveis por cuidar e manter o rebanho com relação à saúde dos animais, especialmente através da vacinação, ordenhar as vacas, amansar as reses que fugiram ou precisam se adaptar à fazenda, marcar as reses com o intuito de evitar a mistura com outros rebanhos e finalmente a soltura, que é realizada quando o bezerro passou pelo desmame, foi marcado e pode ficar solto na caatinga para pastar. Os vaqueiros ainda são responsáveis por conduzir o gado na busca de água em locais mais distantes e informar ao proprietário sobre o estado do rebanho. Durante o período de chuvas, os animais são conduzidos às "mangas" enquanto que os bezerros ficam presos para facilitar a ordenha das vacas. (ANDRADE, 1986).

No que concerne ao vaqueiro urbano ou ao vaqueiro de pista, como também são chamados, a rotina com os animais é mais esparsa, restringindo-se apenas aos eventos de Pega de Boi e Vaquejada. Mesmo sendo realizadas com bastante frequência, essas formas de competição estão longe de serem comparadas com a relação com os animas na rotina diária dos vaqueiros do campo. Da mesma forma que estes últimos, o perfil do vaqueiro urbano também é extremamente heterogêneo, com vaqueiros de diferentes idades, gênero, locais de moradia e formação social e econômica.

Os torneios da Pega de Boi e da Vaquejada foram criados a partir de necessidade de juntar o gado que era criado solto em campos vastos, sem limites de cercas ou currais, e que se espalhava em busca de pasto e água, chamado pelos vaqueiros de apartação. A apartação surgia no fim de uma estação, quando um proprietário de alguma fazenda precisava juntar seu gado espalhado, ele convocava outros proprietários de fazendas e vaqueiros da região para, juntos, "apartar" o gado, o que significava colocar, em uma malhada ou rodeador, o 
gado encontrado, enquanto alguns vaqueiros fechavam o cerco,e outros continuavam a campear o gado que seria marcado, vacinado, castrado ou ainda ser levado para áreas onde os pastos fossem mais abundantes. A Pega de boi, junto com a vaquejada, ganhou maior visibilidade, conquistando seguidores nas cidades e seus entornos. (ANDRADE, 1986; MENEZES; ALMEIDA, 2008).

Conhecida como "Festa da apartação" ou da separação do gado, as Pega de Boi eram realizadas como uma festa de encerramento de uma etapa de trabalho dos vaqueiros, que consistia em reunir o gado, marcar, castrar, tratar as feridas, vacinar, trabalho essencial. Assim, no período das chuvas ou no momento da comercialização, o fazendeiro proporcionava festejos para reaver as rezes perdidas. Andrade (1986) afirma que a apartação é uma festa proporcionada pelo fazendeiro quando tinha a intenção de remanejar seu rebanho ou no momento de marcar o gado para a comercialização.Surgiam assim as Pegas de Boi, que têm sua origem na procura dos animais bravios na caatinga. Essas competições serviam não só para mostrar a habilidade dos vaqueiros no manuseio do gado, mas funcionavam também como uma vitrine dessas habilidades e a conquista de prêmios. Hoje em dia, os vaqueiros, que recebem um salário, afirmam que as competições servem para ajudar na renda da família, ou reconhecimento através de troféus ou prêmios. (SILVA, 2008).

Dessa forma, os proprietários das fazendas locais passaram a organizar torneios de Pegas de Boi, que hoje são organizadas por pessoas experientes ou associações, como é o caso da associação dos vaqueiros em Serra Talhada. Além disso, os eventos ficaram mais competitivos, com vaqueiros vindo de diversos municípios e arredores no sertão do Pajeú, possuindo inclusive calendário e regulamentos. Além da Pega de Boi, há também as Vaquejadas, e mesmo sendo realizadas como competição, guardam grandes diferenças em relação à primeira. Isso se dá basicamente em sua contextualização, sendo a Pega de Boi predominante no sertão do Pajeú e Itaparica, enquanto que a vaquejada é mais presente no resto do estado de Pernambuco. Ambas as competições e eventos também divergem em suas estruturas, sendo a Pega mais próxima ao manuseio do gado no campo, dentro da caatinga, enquanto que a vaquejada é definida numa arena.

A vaquejadaé descrita pelos vaqueiros como um esporte, no qual dois vaqueiros (o puxador e o bate-esteira) procuram derrubar a rês numa faixa de terra, também chamada de pista. A análise e a pontuação variam de acordo com os critérios válidos para a derrubada do gado na faixa apropriada para a queda, com dez metros de largura, desenhada com cal no chão da pista. Diferente da Pega de Boi, a vaquejada é marcada pela padronização do espaço e da arena, onde ficam a pista e as arquibancadas. A ideia é que apenas vaqueiros profissionais tomem parte nas competições do evento, já que são caracterizados por grandes investimentos e atraem um grande público no Nordeste.

Mas as Vaquejadas não se resumem apenas a festas, pois também englobam um lado negativo, que são as denúncias sobre maus tratos com o gado antes e depois que ele é colocado na arena. Thomas Silva (2008), sob a ótica jurídica, cita Geuza Leitão (2007) e Castelo Branco (2007) respectivamente, argumentando que "é crime previsto no Art. 32 da Lei de Crimes Ambientais (Lei 9605/1998) e Art. 225, § $1^{\circ}$, VII da Constituição Federal. Estudos da UIPA e pareceres de médicos veterinários dão conta da violência e dor sofridos pelos animais numa vaquejada", e que "de acordo com a Lei no . 9.605, de 1998, artigo 32 , considera-se crime de crueldade, esse tipo de tratamento dado aos animais em vaquejada". (SILVA, 2008).

Já nas Pega de boi, a performance dos vaqueiros funciona de maneira mais aproximada daquilo que os vaqueiros do campo vivem em suas rotinas diárias, ou seja, eles têm que buscar a rês dentro da vegetação da caatinga e 
correr os mesmos riscos diários dos vaqueiros que lidam com essa profissão. Por conseguinte, nas Pegas de Boi não há agressividade com os animais, uma vez que os vaqueiros para vencer a competição necessitam apenas de encontrar a rês no campo. Localizada a rês, basta que o vaqueiro pegue o colar de couro do chocalho do animal e traga para os juízes da prova, deixando o animal no local encontrado, sem precisar derrubá-lo ou causar qualquer tipo de mau trato.

Dito isso, é importante mencionar o fato de que a relação entre o vaqueiro e o gado é fortemente interpolada com a relação do vaqueiro e seu cavalo, já que essa relação é crucial para o ato de campear e encontrar a rês dentro da vegetação fechada da caatinga. Segundo um dos vaqueiros com quem conversei, se o cavalo for bom e bem treinado, a campeada se torna menos perigosa, pois o cavalo conhece os caminhos que tem de pegar para chegar até a rês desgarrada. Por essa razão, se o cavalo for pouco treinado e não tiver experiência, os acidentes são muito mais frequentes.

\section{O SOM NA RELAÇÃO ENTRE VAQUEIROS E SEUS ANIMAIS}

O som na vida do vaqueiro é de crucial importância, pois é essencial para o vaqueiro que vive da profissão nas fazendas de gado. A comunicação entre o vaqueiro e o gado é feita através da voz do vaqueirode um ladoe,do outro, os sons emitidos pelos chocalhos pendurados nos pescoços dos animais. Cada vaqueiro possui sua forma pessoal e peculiar de chamar o gado, sendo considerado um aboio ou não, segundo me foi informado. Esse aboio ou chamado pode ser na forma de som entoado pelo vaqueiro que é, segundo eles, imediatamente reconhecido pelo gado. Alguns consideram esse aboio ou chamado como melancólico ou triste, e que em alguns casos pode até se tornar uma melodia cantada com verso, chamada por eles de "toada".

Há pouquíssimos trabalhos realizados sobre o aboio, o que torna sua definição difícil de ser esclarecida, até mesmo pelos vaqueiros com quem conversei. Na já clássica definição de Mário de Andrade, que pesquisou extensivamente a música do Nordeste durante a década de 1930 com sua Missão de Pesquisas Folclóricas, ele define o termo aboio da seguinte forma:

"O marroeiro (vaqueiro) conduzindo o gado nas estradas, ou movendo com ele nas fazendas, tem por costume cantar. Entoa um arabesco, geralmente livre de forma estrófica, destituído de palavras as mais das vezes, simples vocalizações, interceptadas quando senão por palavras interjectivas, "boi êh boi", boiato, etc. O ato de cantar assim chama de aboiar. Ao canto chama de aboio". (ANDRADE, 1989, p. 1-2).

O maestro Guerra-Peixe (1954, p. 1), por sua vez, afirma que o aboio vem do ato de aboiar, que, segundo ele, "é o ato de reunir o gado, mantendo-o manso e ordenado", ou seja, de "conduzir a boiada de um para outro lugar, servindo, ainda, para embelezar o aboiar". Mas, aboio também significa cantoria que é feita pelos vaqueiros, que em alguns casos admitem o uso de poesia na cantoria, passando a ser chamada de toada e não mais aboio. E, confirmando o que ouvi de alguns vaqueiros, é necessário que a boiada atenda a um aboio característico de um determinado vaqueiro a fim de que os animais se orientem através do seu canto ou chamado, sendo assim apartados dos animais de outras fazendas. A respeito dessa particularidade Guerra Peixe (1954, p.3) coloca a seguinte observação: 
“Cada vez que um vaqueiro precisa ser substituído, por morte deste ou por qualquer motivo, o substituto deve aprender a cantar o abôio(sic) característico da fazenda emitindo a mesmíssima interpretação que o antigo vaqueiro lhe imprimia. Comumente o novo responsável pelo mister já é outro vaqueiro da mesma fazenda, bem informado da maneira como era entoado o cântico. Mas se o novo vaqueiro não procurar ou não souber imitar o anterior, poderá estar sujeito à fúria da boiada, pois esta, estranhando o seu aboiar, pode tomá-lo por algum intruso em seu caminho e as [vingadas] [?] serão dadas na primeira oportunidade (grifo do autor)".

Oneyda Alvarenga e Câmara Cascudo entendem o aboio com música de trabalho vaqueiro, isto é, uma música que é executada durante a campeada, quando o gado é levado de um local a outro. Alvarenga (1982, p. 259) diz que "os aboios constituem um dos mais importantes grupos dos nossos cantos de trabalho rurais" e que os vaqueiros comumente o utilizam para conduzir os rebanhos bovinos no Norte e Nordeste. Já Câmara Cascudo (s/d, p. 21-22) o define como:

"canto sem palavras, marcado exclusivamente em vogais, entoado pelos vaqueiros quando conduzem o gado. Dentro desses limites tradicionais, o aboio é de livre improvisação, e são apontados os que se salientam como bons no aboio. O canto finaliza sempre por uma frase de incitamento à boiada: ei boi, boi surubin, ei lá (grifo do autor)".

E mais,

"No sertão do Brasil o aboio é sempre solo, canto individual, entoado livremente. Jamais cantam versos, tangendo gado. O aboio não é divertimento. É coisa séria. Velhíssima, respeitada. Abóia-se (sic) no mato, para orientar a quem se procura. Abóia-se (sic) sentado no mourão da porteira, vendo o gado entrar. Abóia-se (sic) guiando o boiadão nas estradas, tarde ou manhã. Serve para o gado solto do campo e também para o gado curraleiro, vacas de leite, mas em menor escala".

Mendes (2015, p. 25-26) ainda faz uma distinção entre diferentes tipos de aboio, os quais ele classifica como "aboio de trabalho", "aboio de festivais competitivos e do espetáculo", o "aboio da indústria cultural" e a "toada". No primeiro caso, o aboio de trabalhoé uma "... a palavra aboio se refere às melodias e interjeições feitas de improviso para a condução do gado". No segundo, o aboio se refere a 'toda a manifestação musical do evento. Por isso, eles chamam o evento de "Festival de Aboio", No aboio da indústria cultural, ele passa a ser entendido como "uma gravação de uma toada de vaquejada, muitas vezes com acompanhamento instrumental e tratamento do áudio em estúdio". Por fim, a toada a que já havia me referido antes, é "manifestação musical quando a mesma possui versos e rimas e tem uma 'aura' de produto acabado". Como se percebe, em algunscasos o aboio pode significar uma forma de comunicação entre o vaqueiro e o rebanho sob sua vigília, mas nem por isso pode ser negligenciado, pois interfere de volta nas suas origens, numa mão de via dupla.

O aboio é uma particularidade que nem todos vaqueiros possuem. Em conversa com alguns vaqueiros, eles me informaram que existe o aboio simples, que funciona como um chamado e é feito por muitos vaqueiros, mas há também o aboio musical, que é quase como um canto e que, de acordo com eles é um dom que apenas alguns conseguem ter, especialmente se há poesia envolvida no aboio, ou seja, a toada. Os animais, em contrapartida, "respondem" aos vaqueiros através de seus chocalhos, sendo seus sons reconhecidos facilmente por eles. 


\section{CONSIDERAÇÕES FINAIS}

Como visto até aqui, a relação dos vaqueiros com seus animais, o gado e seu(s) cavalo(s), traduz um grande número de questões pertinentes aos Estudos da Relação Humano-Animal. Em primeiro lugar, vemos como a pecuária, através da criação de gado em grande extensão do interior do nordeste do Brasil, ajudou a desenvolver, mesmo que limitadamente, uma região que de outra forma permaneceria isolada no tempo. A pecuária hoje não só tem expressiva relevância para o comércio do gado internamente, como também externamente, ainda que tenhamos de levar em conta todas as críticas relacionadas à forma como os animais são abatidos.

O que precisa ser contemplado neste momento é em que direção os estudos da Relação Humano-Animal irão se voltar nos próximos anos e décadas. Mesmo que nós humanos não necessitemos dos animais para sobreviver, diante de uma imensa variedade de alimentos e produtos sintéticos, não se deve esperar que os animais deixem sua função de supridores das nossas necessidades tão cedo. Nem que os laboratórios abram mão de seus experimentos com cobaias e experiências nunca divulgadas. Mas há também os casos em que os animais continuarão a exercer seu papel de sujeitos em nossas sociedades, mostrando o grau de importância que nossas relações com eles estão longe de findar.

A relação entre os vaqueiros e o gado ilustra apenas uma parte do espectro de abordagens que o campo pode proporcionar. A palavra chave na definição dos Estudos da Relação Humano-Animal é de fato "relacionamento". O campo é hoje o único que investiga diretamente as relações entre animais humanos e não-humanos e seu ambiente dentro das pesquisas acadêmicas, estabelecendo as mais variadas formas de laços, conexões, interações e comunicações entre humanos e animais não-humanos.

Poucos dias antes de me dedicar a este artigo, descobri em uma conversa informal com os vaqueiros de Serra Talhada que, apesar da vida de vaqueiro ser um universo predominantemente masculino, havia, no entanto, mulheres que se dedicavam ao mundo dos vaqueiros e que além de serem hábeis com o manuseio dos animais, eram também respeitadas pelos pares. Mas isso é um tema para outro viés na minha pesquisa sobre os vaqueiros do Sertão do Pajeú, no interior de Pernambuco.

\section{NOTAS DE FIM}

${ }^{1}$ Conforme Valle (2007, p. 87), "o período de duração de uma "campeada" pode variar em função do local onde o gado se encontra pastando e bebendo água, e ainda em função da finalidade a que procura atender. Deste modo, o andamento das "campeadas" pode levar de um a muitos dias, até semanas, e percorrer dezenas de quilômetros".

2 Andrade (1986) define as "mangas" como áreas de melhor pastagem e que, hoje em dia, têm sido cercadas com arames farpados, reduzindo a liberdade dos rebanhos e causando sérios acidentes com os vaqueiros durante a campeada.

\section{REFERÊNCIAS}

ALVARENGA, Oneyda. Música popular brasileira. São Paulo: Duas Cidades, 1982. 
ANDRADE. Manuel Correia. A Terra e o Homem no Nordeste. São Paulo: ed. Atlas, 1986 [1963].

ANDRADE, Mário de. Dicionário Musical Brasileiro. Belo Horizonte: Itatiaia - São Paulo: editora da Universidade de São Paulo, 1989.

CASCUDO, Luís da Câmara. Dicionário do Folclore Brasileiro. 10. ed.

Ediouro, Rio de Janeiro, s/d, ISBN 85-00-80007-0.

DEMELLO, Margo. Animals and society: an introduction to human-animal studies. New York: Columbia University Press, 2012.

DEMELLO, Margo; JOSEPH, Cheryl. Human-Animal Studies - Exploring the Animal-Human bond through a sociological lens. NY: Lantern, 2010.

EVANS-PRITCHARD, E. The Nuer: A description of the modes of livelihood and political institutions of a Nilotic people. Oxford: Clarendon Press, 1950.

FURTADO, C. Formação Econômica do Brasil. São Paulo: Companhia das Letras, 2007 [1959].

GEERTZ, C. A Interpretação das Culturas. Rio de Janeiro: LTC, 1989.

GUERRA-PEIXE, Variações Sobre o Boi. O Tempo. São Paulo, 14 de novembro de 1954.

INGOLD, Tim. Introduction. In INGOLD, Tim (ed.). What Is an Animal? p. 84-99. London: Routledge, 1988.

KIRKSEY, Eben; HELMREICH, Stefan. The emergence of multispecies ethnography. Cultural Anthropology, v. 25, Issue 4, p. 545-576, 2010.

LEWGOY, Bernardo; SORDI, Caetano; PINTO, Leandra. Domesticando o Humano para uma Antropologia Moral da Proteção Animal. Ilha, v. 17, n. 2, p. 75-100, ago./dez. 2015.

MARVIN, Garry; MCHUGH, Susan. In it together: an introduction to human- animal studies. In: MARVIN, Garry; MCHUGH, Susan. Routledge handbook of human-animal studies. New York: Routledge, p. 1-9, 2014.

MENDES, Adriano. Aboio no Sertão Paraibano: Um canto no trabalho, um trabalho no canto. Dissertação (Mestrado em Música) Universidade Federal da Paraíba-UFPB, João Pessoa, 2015.

MENEZES, Sonia; ALMEIDA, Maria Geralda. Vaquejada: a pega de boi na caatinga resiste no sertão sergipano. Vivência, n. 34, p. 181-193, 2008.

MULLIN, Molly. Mirrors and Windows: Sociocultural Studies of

Human-Animal Relationships. Annual Review of Anthropology, p. 28:201224, 1999.

. Animals in Anthropology. Society and Animals 10(4):378-393, 2002.

NUNES, Aldo. A (Re)Pecuarização Do Semiárido Nordestino: Reconversões Produtivas Entre Agricultores Familiares Do Pajeú (PE). Dissertação (Mestrado em Ciências Sociais) Universidade Federal de Campina Grande-UFCG, Campina Grande, 2011.

PRADO JUNIOR, C. História Econômica do Brasil. São Paulo: Brasiliense, 1985 (1945).

RAPCHAN, E. S.; NEVES, W. A. Etnografias sobre humanos e não humanos: limites e possibilidades. Revista de Antropologia, v. 57, n. 1, p. 33-84, 2014.

REGAN, T. The Case for Animal Rights. Berkeley: University of California Press, 1984.

SHAPIRO, K. Human-Animal Studies: Growing the field, applying the field. Ann Arbor, MI: Animals and Society Institute, 2008.

SHAPIRO, K.; DeMELLO, M. The State of Human-Animal Studies. SocietyandAnimals, 18, p. 307-318, 2010. 
SILVA, Jacionira.Arqueologia no médio São Francisco. Indígenas, vaqueiros e missionários. Tese (Doutorado em História), Universidade Federal de Pernambuco-UFPE, Recife, 2003.

SILVA, Thomas de Carvalho. Vaquejadas: a prática da Vaquejada à luz da Constituição Federal de 1988. Conteúdo Jurídico, Brasília-DF: 16 dez. 2008. Disponível em: $<$ http://www.conteudojuridico.com.br/?artigos\&ver $=2.22452 \& \mathrm{seo}=1>$. Acessoem: 30 abr. 2016.

SINGER, Peter. Animal Liberation. London: Harper Collins, 1990.

TAYLOR, Nik. Introduction. In: TAYLOR, Nik e SIGNAL, Tania (ed.). Theorizing animals: re-thinking humanimal relations. Leiden - Boston: Brill, p. 1-17, 2011.

VALLE, Yumma. Vaqueiros do Sítio do Meio (Lagoa Grande/PE) e mamiferos nativos das Caatingas Pernambucanas: percepções e interações. Dissertação (Mestrado) Universidade Federal de Pernambuco. CFCH. Gestão e Políticas Ambientais. Recife, 2007.

WALDAU, Paul. Animal Studies: An Introduction. Oxford University Press. March 2013. 